\title{
ISSUES TO BE ADDRESSED IN THE DESIGN AND FABRICATION OF ULTRALIGHTWEIGHT, METER CLASS OPTICS
}

\author{
Gary C. Krumweide \\ Director, Advanced Programs \\ Composite Optics, Incorporated \\ 9617 Distribution Avenue \\ San Diego, CA 92121 \\ $619 / 621-5700$
}

\begin{abstract}
There is a growing need for large aperture, ultralightweight, deployable optics (mirrors) for various science, military and commercial compact satellites (Pleimann 1997). This paper will examine the engineering and manufacturing considerations that must be addressed in order to satisfy the requirements for these sought after optics. In order to limit the scope of this paper, only Graphite Fiber Reinforced/Polymer Matrix Composites (GFR/PMC) will be under consideration because of the potential to satisfy ultralightweight mirror requirements $\left(5-10 \mathrm{Kg} / \mathrm{m}^{2}\right)$ (Kasl 1997). The requirements associated with specular mirror concepts that Composite Optics, Incorporated (COI) has proposed to Air Force Research Laboratory (AFRL/NS) and NASA Langley Research Center for visible range optics and LIDAR (light bucket) optics, respectively, will also be our interest. Moreover, it is the intent of this paper to illustrate how COI's proposed design/manufacturing concepts for visible and LIDAR optics have evolved based on overcoming, or working around, material constraints and/or undesirable characteristics associated with GFR/PMC.
\end{abstract}

\section{INTRODUCTION}

Given the need for ultralightweight, meter class mirrors (optics) for various science, military, and commercial compact satellite applications, COI has set out to address several challenging issues in the production of such mirrors. The feasibility of producing visible range mirrors can be attributed to recent technology advances in materials, innovative design/fabrication approaches, moisture barrier development and mirror post-machining processes. These recent technological advances and several supporting Small Business Innovative Research (SBIR) Programs (see Table 1) have allowed COI to propose a mirror design/fabrication concept that provides a "workaround" solution to the following issues:

1. How to employ an anistropic laminate of GFR/PMC in a mirror or mirror substrate that requires micron-level dimensional stability.

2. How to employ a hygroscopic laminate of GFR/PMC in a mirror or mirror substrate that requires micron-level dimensional stability.

3. How to match the Coefficient of Thermal Expansion (CTE) of glass (necessary to produce visible range [ $2 / 40$ RMS] optical surfaces) with GFR/PMC (needed as a lightweight substrate).

4. How to assure GFR/PMC will not microcrack.

5. How to meet $5-10 \mathrm{Kg} / \mathrm{m}^{2}$ weight requirements.

6. How to obtain/maintain figure ( $\lambda / 40$ RMS visible optics and $2 / 2$ RMS LIDAR optics) during assembly of the optics.

7. How to mount optics without distortion or distortions of operation.

8. How to assure long-term stability of optics. 
9. How to produce ultralightweight optics that are dynamically stable.

10. How to produce large, ultralightweight optics for visible range and LIDAR economically.

These types of issues have been a concern for many years when using GFR/PMC for dimensionally stable structures and will be addressed in the ensuing discussion (Krumweide 1988).

In order to illustrate how a specific issue (above) is being addressed for the two mirrors (i.e., visible, LIDAR), a design concept for each will be presented and the various features of each reviewed for their function and/or resolution of the issue at hand.

TABLE 1. COI SBIRs Supporting Mirror Development Technology.

\begin{tabular}{|l|c|l|l|l|}
\hline NAS8-39826 & 1994 & Phase I & $\begin{array}{l}\text { NASA/Jet Propulsion } \\
\text { Laboratory }\end{array}$ & $\begin{array}{l}\text { Graphite Fiber Reinforced Composite } \\
\text { Submillimeter Reflectors }\end{array}$ \\
\hline NAS8-40170 & 1993 & Phase II & $\begin{array}{l}\text { NASA Marshall Space Flight } \\
\text { Center }\end{array}$ & $\begin{array}{l}\text { Thermally Stable, Large Aperture, High } \\
\text { Resolution Optics }\end{array}$ \\
\hline NAS8-40511 & 1994 & Phase I & $\begin{array}{l}\text { NASA/Marshall Space Flight } \\
\text { Center }\end{array}$ & $\begin{array}{l}\text { Fiber Print Thru Avoidance and Stability } \\
\text { Enhancement Using Carbon Fiber Composites } \\
\text { for Grazing Incidence X-Ray Optics }\end{array}$ \\
\hline NAS7-1259 & 1994 & Phase I & $\begin{array}{l}\text { NASA/Jet Propulsion } \\
\text { Laboratory }\end{array}$ & $\begin{array}{l}\text { Graphite Fiber Reinforced Composite } \\
\text { Submillimeter Reflectors }\end{array}$ \\
\hline NAS8-97202 & 1997 & Phase I & $\begin{array}{l}\text { NASA/Marshall Space Flight } \\
\text { Center }\end{array}$ & $\begin{array}{l}\text { Lightweight Carbon Fiber Composite Mirror } \\
\text { Fabrication Using Advanced Core Technology }\end{array}$ \\
\hline NAS8-97151 & 1997 & Phase I & $\begin{array}{l}\text { NASAMMarshall Space Flight } \\
\text { Center }\end{array}$ & $\begin{array}{l}\text { Barrier Coatings That Minimize Hygroscopic } \\
\text { Change Of Ultra High Modulus Carbon } \\
\text { Reinforced Cyanate Ester Resins }\end{array}$ \\
\hline NAS8-97274 & 1997 & Phase II & $\begin{array}{l}\text { NASAMMarshall Space Flight } \\
\text { Center }\end{array}$ & $\begin{array}{l}\text { Fiber Print Through for Grazing Incidence X- } \\
\text { Ray Mirrors }\end{array}$ \\
\hline F29601-97-C-0084 & 1997 & Phillips Laboratory & $\begin{array}{l}\text { Development of Lightweight Visible Range, } \\
\text { Meter Class Optics Using PM/CFC) Materials }\end{array}$ \\
\hline
\end{tabular}

\section{DISCUSSION}

The visible range optics and LIDAR optics will be discussed separately in order to understand their differences (i.e., design/fabrication/assembly).

\section{Visible Range Optics}

The design concept for this mirror is mostly driven by the high resolution requirement defined by the AFRL/VS. Table 2 lists the current SBIR Phase I mirror requirements provided by AFRL/VS (Pleimann 1997). The surface roughness of 10-20 angstroms figure of $\lambda / 40$ RMS and areal density of $5-8 \mathrm{Kg} / \mathrm{m}^{2}$ suggests a hybrid design of ULE glass and GFR/PMC be considered.

TABLE 2. SBIR Phase I Mirror Requirement.

\begin{tabular}{|l|l|}
\hline Definition & Requirement \\
\hline Size & $0.25 \mathrm{~m}$ diameter substrate \\
\hline Shape & Spherical \\
\hline Radius of Curvature & $2 \mathrm{~m}$ \\
\hline Areal Density $\left(\mathrm{Kg} / \mathrm{m}^{2}\right)$ & $5-8$ \\
\hline Surface Roughness (angstroms) & $10-20$ \\
\hline Figure & $\lambda / 40 \mathrm{rms}$ \\
\hline Wavefront & $\lambda / 20 \mathrm{rms}$ \\
\hline Spectrum & Visible \\
\hline Temperature Range $(\mathrm{K})$ & $\pm 5^{\circ}$ from room temperature \\
\hline Survivable Thermal Range $(\mathrm{K})$ & $268^{\circ}$ to $328^{\circ}$ \\
\hline
\end{tabular}




\begin{tabular}{|l|l|}
\hline Definition & Requirement \\
\hline Testing & Optical axis in vertical position \\
\hline Launch Environment & Space Shuttle \\
\hline First Mode & $>80 \mathrm{~Hz}$ w/free-free mount \\
\hline Scalability & Multiple meter class \\
\hline
\end{tabular}

Figure 1, which COl calls its Fixed Third Surface Mirror Design, has been selected by the AFRL/VS for evaluation for Ultra-LITE (a sparse aperture, deployable, ground-based test program). The mirror is $0.25 \mathrm{~m}$ diameter and has a $2 \mathrm{~m}$ radius of curvature (spherical).

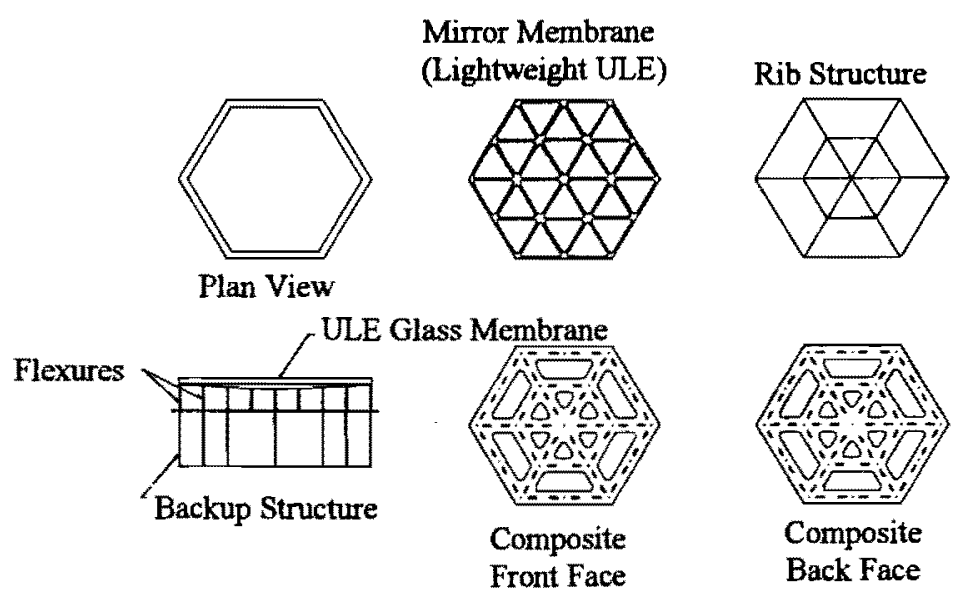

FlGURE 1. Fixed Third Surface Mirror Design.

The lightweighted ULE glass membrane, with its isogrid pattern, mounts on flexures (located at each node) protruding out of the GFR/PMC back-up structure. This back-up structure consists of GFR/PMC facesheets (laminate) and GFR/PMC ribs (laminate). The ribs form a similar isogrid pattern that matches the isogrid pattern of the lightweighted ULE glass membrane. Recesses, waterjet machined when the basic isogrid node is machined (by Waterjet Technologies, Inc.), provides a bonded structural interface between the ULE glass and the dowel-like flexures. The flexures are uni-directional GFR/PMC. The lockout position of each flexure, by "wick bonding" at both the top and bottom skin, is its only faying surface with the back-up structure. Given this basic design approach, the issues presented in the introduction will now be addressed.

Anistropic laminate workaround: Because through-the-thickness CTE properties of a GFR/PMC are approximately $36 \mathrm{ppm} /{ }^{\circ} \mathrm{C}$, while its in-plane properties for a candidate material are approximately $-0.30 \pm 0.2$ $\mathrm{ppm} /{ }^{\circ} \mathrm{C}$, construction of the back-up structure design has to "null out" the effect of the high through-the-thickness CTE. Since micron stability is desired, this CTE of $36 \mathrm{ppm} /{ }^{\circ} \mathrm{C}$ with operational temperature variations from room temperature $\pm 5^{\circ} \mathrm{C}$ is undesirable. By using thin ribs $(>0.75 \mathrm{~mm}$ thick) that bond to the inside surfaces of the facesheets and not bonding the ribs at the node points (where they cross one another in the isogrid), the distorting effect of through-the-thickness is eliminated. It should be noted that the symmetry of the back-up structure design and manufacturing approach assures greater dimensional stability of this structure.

Hygroscopic laminate workaround: The effects of moisture ingress and egress (CME) on GFR/PMC is, by 2 or 3 orders of magnitude, a greater problem than CTE. This is true even when Polycyanate Ester resins are used; which have one-third lower (CME) than Epoxy resins. For this design, $\mathrm{COI}$ is employing, a moisture barrier to eliminate the need to do all testing of the mirror assembly in a vacuum, or a very low relativity humidity (RH) environment. 
Otherwise, the mirror would ingress the moisture typical of an assembly environment ( $30-60 \% \mathrm{RH})$ and egress the moisture when operating in a dry space environment $(0 \% \mathrm{RH})$. Figure errors would result unless the mirror is final figured and operates in a dry $(0 \% \mathrm{RH})$ environment.

COI moisture barriering methods have been used successfully. Figure 2 shows moisture barriered telescope assembly coupons fabricated by COI in 1985 (Krumweide 1989). Most recent testing of moisture barriers applied to coupons indicates even better moisture barriering results.

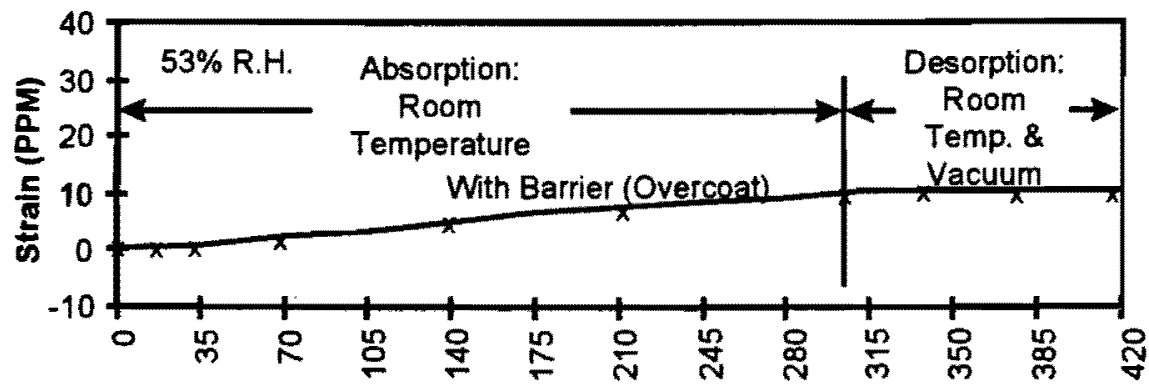

Elapsed Time (Days)

FIGURE 2. Moisture Barrier on .04 inch thick P75/930 Gr/E laminate.

For the back-up structure shown in Figure 1 , a $100 \%$ moisture barrier coverage is planned after the structure is assembled.

CTE mismatch workaround: $C O I$ has been very successful in tuning a GFR/PMC laminate CTE to a near zero CTE - meaning a CTE of $0.0 \pm 0.024 \mathrm{ppm} /{ }^{\circ} \mathrm{C}$ is possible, limited mostly by the measurement accuracy of our Laser Optical Comparator (LOC). A workaround method that is appropriate for the Fixed Third Surface Mirror, shown in Figure 1, is to measure the lightweighted ULE glass membrane "side-by-side" with the moisture barriered backup structure using a tilt mirror across the two parts; a typical measurement technique for the LOC. Any substantial difference in CTE can be verified and corrected.

Another workaround plan is the use of flexures. These dowel-like flexures will mitigate any CTE mismatches that are built into the assembled mirror or result from long-term exposure to the space environment (i.e., radiation effects).

Microcracking workaround: $\mathrm{COI}$ incorporates fiber/resin combinations necessary to prevent microcracking (Krumweide 1991).

Weight requirement of $5-10 \mathrm{Kg} / \mathrm{m}^{2}$ : This is the most difficult requirement to satisfy because the lightweighted ULE glass is over half the weight of the design. The glass is waterjet machined to reduce its basic skin thickness to under $2 \mathrm{~mm}$ which is optional for this post-machining process and for maintaining surface figure of the mirror.

The back-up structure has been designed to remove all the unnecessary facesheet material (top and bottom cutouts) and still provide the desired stiffness. Note: Relatively large spacing between facesheets.

Surface figure of $\lambda / 40 \mathrm{rms}$ : Four steps are necessary to assure this requirement is achievable. The first is to support the ULE glass membrane on flexures at isogrid node points. The second is to machine the lightweight ULE glass to a fraction of a wave $\lambda \mathrm{ms}\left(\approx \lambda_{2}\right)$. The third is to bond flexures only to the membrane and, yet, unattached (unbonded) to the back-up structure until the original (or near original) surface accuracy is adjusted into the ULE glass membrane via the axial movement of the flexures. Here adjusters are attached to each flexure and systematically activated while surface figure is monitored using a laser interferometer. The fourth step is to post machine the lightweighted ULE glass. 
Mounting distortions: The use of a Fixed Third Surface Mirror design is of importance here. The flexures will compensate for any CTE mismatch type of distortions associated with mounting. It is assumed that a 3-point (determinate) mount system will be employed.

Long-term stability: As mentioned previously, the use of flexures is to mitigate long-term distortion due to radiation effects on the polymer matrix.

Dynamic stability: The diameter of the individual flexure to provide adequate stiffness for 1 " $\mathrm{G}$ " sag and produce a frequency of approximately $250 \mathrm{~Hz}$ will also provide enough flexibility to compensate for a differential CTE between the glass and GFR/PMC $\left(0.04 \mathrm{ppm} /{ }^{\circ} \mathrm{C}\right)$ and maintain figure.

Economical design: By using flat laminate construction techniques for the back-up structure, the design is very economical. That is, no expensive tooling (PDMO) is required. Also, the capability of cutting enough parts from a single flat laminate to make several mirrors is possible. This design requires no master mold, for mirror figure, as is necessary in a replicated mirror figuring processes.

Thus, an ultralightweight visible optic, as illustrated in Figure 1, may be possible using GFR/PMC if attention is given to the undesirable characteristics of this GRF/PMC material.

\section{LIDAR (Lightweight) Optics}

Figure 3 depicts the Fixed Third Surface Mirror being proposed for a NASA LaRC LIDAR Mirror concept. The similarity to the AFRL/VS mirror is not coincidental but is intended to get some synergism from these two programs. COI proposed to utilize the same back-up structure for both mirrors. So the primary difference is that the ULE glass membrane for the AFRL/VS mirror is replaced with a thin GFR/PMC membrane for the NASA LaRC mirror. The thin membrane is the same material and layup used for the flat facesheet laminates in the backup structure. Another minor difference is that a circular doubler (doughnut-shaped) made from the same membrane (outer trim of basic laminate) is bonded to the top of each flexure and to the outer surface of the membrane itself. Injection of a "wicking adhesive" into the faying surface between a fully moisture barriered membrane and fully moisture barriered flexures, bonds the flexures to the membrane and its doubler. Given this basic design approach, the issues presented in the introduction will now be addressed.

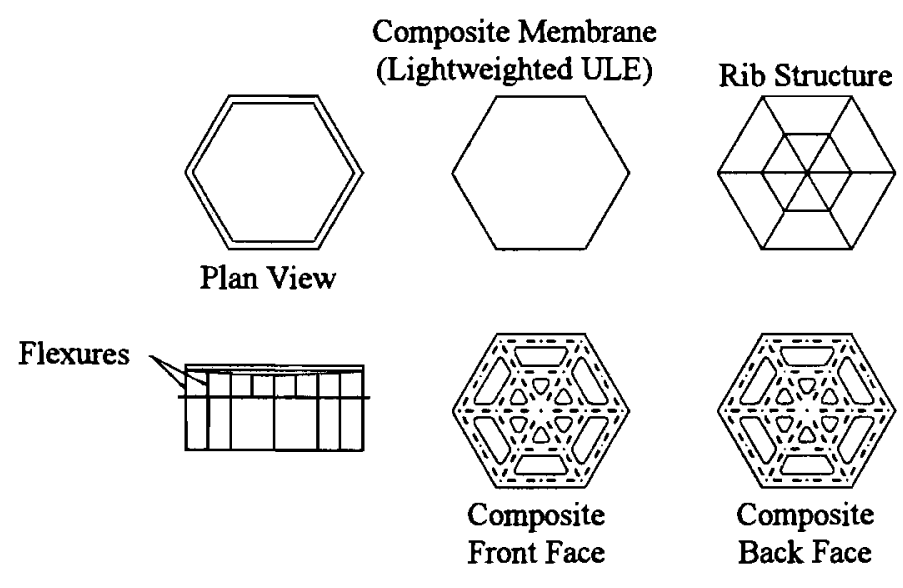

FIGURE 3. Fixed Third Surface Mirror Design

Anistropic laminate workaround: Same as for AFRL/VS Mirror.

Hygroscopic laminate workaround: Same as for AFRL/VS Mirror. 
CTE mismatch workaround: Same as for AFRL/VS mirror except GFR/PMC membrane is measured side-by-side with back-up structure using the LOC. CTE mismatch is expected to be minimal because the materials used in fabricating the membrane and in the fabrication of the back-up structure are essentially the same.

Microcracking workaround: Same as for AFRL/VS mirror.

Weight requirement-of-4-5 $\mathrm{Kg} / \mathrm{m}^{2}$ : The lightweight GFR/PMC membrane allows this type of weight reduction Jver a glass membrane to be achieved.

Surface figure of $\lambda / 2 \mathrm{rms}$ : Several very important factors bear on achieving this requirement. The first is symmetry of the membrane. This includes the incorporation of "rotate and fold" lay-up methods, moisture barrier on both sides of membrane (100\%), and use of the replication adhesive on back surface as is used when front surface when replicated. It should be noted that a Fixed Third Surface Mirror easily allows this manufacturing procedure. The second factor is the use of the replication approach in providing an acceptable smooth, specular surface that, for the most part, does replicate the quantity of glass master mold surface.

The third factor is the use of adjusters attached to the flexures that adjust the membrane to near its original surface figure (when released from the glass mold). The flexures are then locked out with adhesive as described for the AFRL/VS mirror. The use of a laser interferometer is also applicable here.

Mounting distortion: Same as for AFRL/VS mirror.

Long term stability: Same as for AFRL/VS mirror.

Dynamic stability: Same as for AFRL/VS mirror.

Economical design: Same as for AFRL/VS mirror although, the cost of replication adds to the mirrors final cost as does the need for a glass master mold to do this replication on.

As with to the AFRL/VS mirror, it is very possible that a Fixed Third Surface Mirror for LIDAR application can be designed and fabricated if attention is given to the undesirable characteristics of the GFR/PMC material.

\section{CONCLUSIONS}

The ability of a Fixed Third Surface Mirror to meet visible range optics and LIDAR (light bucket) requirements is going to be demonstrated soon. Design and Manufacturing methods are to be incorporated into the mirror to workaround the undesirable characteristics of graphite fiber reinforced polymer matrix composite materials.

\section{Acknowledgments}

The author would like to thank Messrs. Eldon Kasl, Jack Dyer, and Greg Mehle for their support in the preparation of this paper. We also wish to acknowledge the support of the Air Force Phillips Laboratory and NASA Small Business Innovative Research programs.

\section{References}

Kasl, Eldon P. and David E. Crowe, (1997) "A Critical Review of Ultralightweight Composite Mirror Technology," SPIE, Critical Review of Optical Science 1997; CR67.

Krumweide, Gary C. and David N. Chamberlin, (1988) "Adaptation and Innovation in High Modulus Graphite/Epoxy Composite Design: Notes on Recent Developments", SPIE, O-E LASE, Los Angeles, CA, January 1988.

Krumweide, Gary C., Ed A. Derby, and David N. Chamberlin, (1989) "The Performance of Effective Moisture Barriers for Graphite/Epoxy Instrument Structures," SAMPE, Atlantic City, NJ 1989. 
Krumweide, Gary C. and Richard A. Brand, (1991) "Attacking Dimensional Instability Problems in Graphite/Epoxy Structures, " Composite Design, Manufacture and Application, ICCM/8, Honolulu, HI.

Pleimann, Mark E. (1997) "Lightweight Meter Class Optics," IEEE, Aspen, Colorado, March 1998. 